\title{
The Kansas City Meeting of the American Association.
}

THE annual meeting of the American Association for the Advancement of Science was held at Kansas City, Missouri, December 28, 1925-January 2, 1926. This gathering was the eighty-second meeting of the Association. With it met twenty-nine scientific societies. The total registered attendance was I93r. The total number of papers read was 985 .

The policy of the American Association differs from that of the British Association in encouraging the reading in sectional meetings of large numbers of communications, especially many by younger scientific workers. In another respect, however, the practice of the British Association was followed to advantage at Kansas City, namely, in that there were a number of evening and afternoon lectures specially arranged for the general public, seven in all. All sessions of sections, and the various society meetings, were open to the public. Several radio talks were arranged, and popular accounts of a large number of the papers were prepared for wire and mail service to the daily press by a local publicity committee and by Science Service, of Washington.

The address of the retiring president of the American Association, Dr. J. McKeen Cattell, editor of Science and the Scientific Monthly, was delivered on the evening of the opening day. Dr. Cattell spoke on "Some Psychological Experiments," emphasising the application of methods of psychological measurement to modern industrial and social problems.

The paper selected by the award committee for the annual rooo dollar prize of the American Association, as an outstanding contribution to science presented at the meeting, was by Prof. Dayton C. Miller, of the Case School of Applied Science, Cleveland, Ohio, and was entitled "The Michelson-Morley Ether-Drift Experiment, its History and Significance." This paper was read on the Tuesday afternoon, as the presidential address of the American Physical Society.

A paper on a related subject was presented on the following day by Prof. James Pierpont, of Yale University. Prof. Pierpont's address was delivered under the auspices of the American Mathematical Society, as the third annual Josiah Willard Gibbs lecture. His title was "A History of Man's Effort to Solve the Problem of Space, and the Effect of Relativity on Our Views."
Two symposia were led by Prof. Michael I. Pupin, president of the Association. The first was held by the Engineering Section on the Wednesday evening, with a discussion of the relation of engineering to the fundamental sciences. On Thursday afternoon. the Committee of One Hundred on Scientific Research discussed the problem of the encouragement of research workers and of securing co-operation among them. The same question was attacked by Dr. Vernon Kellogg, secretary of the National Research Council, whose address before the Entomological Society of America was entitled " Co-operation or Isolation in Science?"

President F. D. Farrell, of Kansas State Agricultural College, chose as the topic of the fourth annual Sigma Xi: lecture " The Desert Becomes a Garden," telling how the region between the Missouri River and the Rocky Mountains, once marked on the maps as the "Great American Desert," has become one of the most productive agricultural areas in the world. The whole of Wednesday afternoon was devoted to a symposium on prairie ecology, participated in by the botanical and zoological groups.

The newly elected president of the Association is Dr. Liberty Hyde Bailey, formerly dean and director of the New York State Agricultural College at Cornell University, Ithaca, N.Y., well known as the writer and editor of many works on botany and on various aspects of horticulture and agriculture, as well as on rural life in general. Dr. Bailey was also chosen president of the Botanical Society of America.

The next annual meeting of the Association will be held in Philadelphia, and later annual meetings are planned for Nashville, Tennessee; New York City; Des Moines, Iowa; Cleveland, Ohio; and New Orleans, in order. This series of meetings will complete the first of the twelve-year cycles contemplated in the plan inaugurated at the Chicago meeting in r920. According to that plan, the Association is to meet in Chicago, Washington, and New York in rotation once each quadrennium, meetings during the interim years being held in other cities, alternating between larger and smaller places, and between locations in the eastern States and in the west and south.

FRANK THONE.

\section{The Standardisation of Insulin.}

THE position which insulin holds in clinical medicine in the treatment of diabetes would never have become so firmly established if the manufacture of the product had not been controlled. The appearance on the market of preparations of varying potency, perhaps even inactive, would have led to a great delay in the recognition of the usefulness of this compound, perhaps even to a certain amount of scepticism as to its actuality. To control production adequately, then, meant the discovery of a method by which the activity of different samples could be accurately compared and expressed in terms of some known standard. The latter was, and is still, defined in terms of the blood-sugar reducing power of insulin, after injection subcutaneously into normal rabbits. Thus one rabbit unit is that amount of insulin which will reduce the blood-sugar of a 2 kilo. rabbit, starved for twenty-four hours, to the convulsive level of 0.045 per cent. : a clinical unit is one-third of this amount and is the unit which is now generally used. The problem of putting on the market samples of insulin of known and unvarying potency has been simplified by the issue, to those manufacturing the product, of a solid powder (the hydrochloride of insulin), the activity of which has been determined by the authorities controlling the manufacture: this standard powder is now in use in different countries, so that all samples produced should be of the same activity. But this, of course, depends upon the accuracy of the assay of the sample against the standard.

Methods of estimating the activity of insulin preparations have been developed utilising both the blood-sugar reducing property and also a secondary result of this property, the production of convulsions on doses which reduce the blood-sugar to levels of 0.045 per cent. or lower. Owing to the fact that the occurrence of convulsions in a group of animals is much less regular than a fall in the blood-sugar after a dose of insulin, to obtain consistent results very large numbers of animals must be used, either rabbits or, perhaps more conveniently, mice. But even utilising the first method, complications arise from the fact that different animals react very

$$
\text { NO. } 29.38 \text {, VOL. I I } 7]
$$

